\title{
Alleviating effects of the mixture of Elaeagnus multiflora and Cynanchum wilfordii extracts on testosterone deficiency syndrome
}

\author{
Myung-A Jung ${ }^{1}$ (I) $\cdot$ Jawon Shin $^{1} \cdot$ Ara Jo $^{1} \cdot$ Huwon Kang ${ }^{1} \cdot$ Gyuok Lee $^{1} \cdot$ Dool-Ri Oh$^{1} \cdot$ \\ Hyo Jeong Yun ${ }^{1} \cdot$ Sojeong $\operatorname{Im}^{1} \cdot$ Donghyuck Bae ${ }^{1} \cdot$ Jaeyong Kim$^{1} \cdot$ Chul-yung Choi ${ }^{1} \mathbb{C}$
}

Received: 13 October 2020 / Accepted: 27 November 2020 / Published Online: 31 December 2020

(C) The Korean Society for Applied Biological Chemistry 2020

\begin{abstract}
Testosterone deficiency syndrome (TDS), also known as late-onset hypogonadism, is a clinical and biochemical syndrome associated with advanced age and characterized by deficient serum testosterone levels. The Elaeagnus multiflora fruit (EMF) and Cynanchum wilfordii (CW) have been used in traditional herbal medicine. This study aimed to investigate the therapeutic effects of EMF and CW mixtures (at the ratios of 3:7, 5:5, and 7:3) on TDS using TM3 cells and aging male rats. EMF, and mixtures of EMF and CW (at the ratios of 3:7, 5:5, and 7:3) significantly increased testosterone levels in TM3 cells $(p<0.05)$. The rats were orally administered EMCW (EMF and CW mixed at the ratio of $3: 750,100$ and $200 \mathrm{mg} / \mathrm{kg} /$ day) for 4 weeks consecutively. After 4 weeks of EMCW administration, latency time on the rotarod test, and serum testosterone and dehydroepiandrosterone sulfate levels were significantly increased ( $p<0.05$ and $p<0.01$ ). Moreover, the levels of globulin-bound sex hormones were decreased in the EMCW-fed groups. However, prostate-specific antigen levels did not differ among the groups. These results suggest that EMCW can be effectively used to alleviate TDS.
\end{abstract}

Keywords Cynanchum wilfordii $\cdot$ Elaeagnus multiflora $\cdot$ Rotarod test $\cdot$ Testosterone $\cdot$ Testosterone deficiency syndrome $\cdot$ TM3 cells

Myung-A Jung and Jawon Shin are contributed equally to this work.

Chul-yung Choi $(\triangle)$

E-mail: blockstar@hanmail.net

${ }^{1}$ Jeonnam Bioindustry Foundation, Center of Natural Resources Research (JCNR), Jeollanamdo 59338, Republic of Korea

This is an Open Access article distributed under the terms of the Creative Commons Attribution Non-Commercial License (http://creativecommons. org/licenses/by-nc/3.0/) which permits unrestricted non-commercial use, distribution, and reproduction in any medium, provided the original work is properly cited.

\section{Introduction}

Andropause, also called male menopause, is an indefinite syndrome composed of several physical, sexual, and emotional symptoms resulting from a complex interaction among hormonal, psychological, environmental, and physical factors [1]. Andropause causes age-related changes in male hormone levels; as men age, their testosterone levels decline [2]. Morales termed this testosterone decline as testosterone deficiency syndrome (TDS) owing to its simplicity, clarity, and respect for physiological principles [3]. TDS is defined as a clinical and biochemical syndrome associated with advanced age and is characterized by deficient serum testosterone levels [4]. Declining testosterone levels in aging men cause symptoms such as erectile dysfunction (ED), obesity, lack of physical strength, and depression. Total testosterone measurement is the recommended initial test to diagnose hypogonadism. A longitudinal study by Haring et al. reported that low testosterone levels increase the risk of developing metabolic syndrome, thereby underscoring the importance of early hypogonadism diagnoses even among young men [5]. Total testosterone levels decrease by an average of $1.6 \%$ per year, whereas free and bioavailable levels of testosterone decrease by $2-3 \%$ each year. The latter value is higher because aging is associated with increased levels of sex hormone-binding globulin (SHBG) [6]. Production of sex steroids occurs from the adrenal precursors, dehydroepiandrosterone (DHEA) and its sulfate forms (DEHAs). DHEA, an inactive prohormone, is produced by the adrenal glands from cholesterol [7]. The potential role of the prostate in the pathophysiology of TDS have been determined from prostatespecific antigen levels and rectal examination [8].

Elaeagnus multiflora Thunb., commonly called oriental cherry silverberry or gumi, belongs to the family Elaeagnaceae. The species is native to China, Korea, and Japan. Several parts of $E$. multiflora are usually used in traditional Chinese medicine [9-11]. The Elaeagnus multiflora fruit (EMF) is edible and used in small amounts in herbal medicines, particularly owing to its anticancer 
and antioxidant activities [12, 13]. Furthermore, the EMF contains multiple compounds and has numerous physiological effects [1417]. We previously reported that the EMF extracts have antifatigue effects [18]. Cynanchum wilfordii (CW) is used as a in traditional herbal medicine in Korea for the prevention and treatment of diseases. $\mathrm{CW}$ has beneficial effects against numerous conditions including hypertension, hypercholesterolemia, osteoporosis, gastric disorders, and cancer [19-23]. Cynandion A from CW has anti-inflammatory effects [24]. Furthermore, previous studies have reported an increase in sexual behavior and the amelioration of testosterone-induced benign prostatic hyperplasia (BPH) in rat models $[25,26]$. However, no studies have reported the therapeutic effects of EMF and CW extract mixtures on TDS.

In the present study, we determined the optimal mixing ratio of EMF and CW extracts mixed and its effects in vitro, using TM3 Leydig cells. Furthermore, we investigated the effects of the EMCW (EMF and CW mixed at a ratio of 3:7) on TDS in aging male rats undergoing rotarod tests and biomarker analyses.

\section{Materials and methods}

\section{Preparation of EMF}

The EMFs used in this study were obtained from Yeosu-si (Jeollanamdo, Republic of Korea) and authenticated by Dr. Choi at the Jeonnam Bioindustry Foundation, Center of Nature Resources Research (JCNR), Jangheung, Jeollanamdo, Republic of Korea. The plant used for this study was purchased from the Kangwons Medicinal Herb Association (Wonjusi, Kangwondo, Republic of Korea). Air-dried EMF (100 g) was extracted with 20 volumes of water at $100{ }^{\circ} \mathrm{C}$ for $3 \mathrm{~h}$. The extracted solution was filtered, and then concentrated in an evaporator by vacuum freezedrying to obtain EMF (15.4 g). Air-dried CW (100 g) was extracted with 20 volumes water at $100{ }^{\circ} \mathrm{C}$ for $3 \mathrm{~h}$. The $\mathrm{CW}$ was extracted at $100{ }^{\circ} \mathrm{C}$ for $3 \mathrm{~h}$, concentrated, lyophilized, and pulverized under the same experimental conditions. The extracted solution was filtered, and then concentrated in an evaporator through vacuum freeze-drying to obtain $\mathrm{CW}$ (13.4 g). The EMF and CW were mixed at ratios of $3: 7,5: 5$, or $7: 3$. The dried EMF, CW, and mixtures of EMF and $\mathrm{CW}$ (at the ratios of 3:7, 5:5, and 7:3) extracts were stored at 4 until used for the in vitro assays. EMCW was also used for in vivo experiments. The EMCW used in the present study was the same as that used in the clinical trial, which was approved by the institutional review board of Chungnam National University Hospital (clinical trials registration number 2018-05-026).

\section{Cell culture and testosterone levels}

TM3 cells were purchased from the KCLB (Seoul, Republic of Korea) and cultured in DMEM supplemented with $10 \%$ FBS and $1 \%$ penicillin/streptomycin at $37^{\circ} \mathrm{C}$ in a humidified atmosphere containing $5 \% \mathrm{CO}_{2}$. For experiments, cells at early passages were cultured up to $80 \%$ confluence. To investigate changes in testosterone levels in TM3 cells, TM3 cells were seeded at $1 \times 10^{5}$ cells/well in 24-well plates. After $24 \mathrm{~h}$ of incubation, cells were treated with various extracts (EMF, CW, 3:7 mixture, 5:5 mixture, 7:3 mixture) and incubated for $24 \mathrm{~h}$; the supernatant media were then harvested. Testosterone levels in TM3 cells were measured using a testosterone EIA kit (ENZO Life Sciences, Farmingdale, NY, USA) in accordance with the manufacturer's instructions.

\section{Animals}

Male Sprague-Dawley rats (12-week-old, weighing 400-430 g) were purchased from Samtako Bio Korea (Osan, Republic of Korea). Before the start of the experiment, rats were acclimatized to standard feed and reared for 12 weeks until the age of 24 weeks. The rats were housed in plastic cages at a controlled temperature $\left(22 \pm 2{ }^{\circ} \mathrm{C}\right)$ and humidity $(50 \pm 5 \%)$, with ad libitum access to water and food at a 12:12 h light:dark cycle (lights on at 08:00 am). The animals were acclimatized for 1 weeks before the experiments. All experiments were approved by the Institutional Animal Care and Use Committee (IACUC) at Jeonnam Institute of Natural Resources Research (approval no. JINR-1809). All animal experiments were conducted in accordance with the IACUC guidelines.

\section{Experimental groups and drug administration}

The rats were divided into four groups $(n=5)$, and received the fallowing treatments: Group I, vehicle-treated (distilled water; oral administration [p.o.]); Group II, EMCW $50 \mathrm{mg} / \mathrm{kg} /$ day (p,o); Group III, EMCW 100 mg/kg/day (p,o); Group IV; EMCW 200 $\mathrm{mg} / \mathrm{kg} /$ day (p.o.). EMCW was dissolved in distilled water and administered at 9:30 a.m. once a day for 28 days consecutively. Body weighs were measured per week.

\section{Rotarod test}

Rats were placed on a standard five-lane accelerating rotarod apparatus (Jeung Do Bio \& Plant, Seoul, Republic of Korea). Rats were tested twice at an accelerating speed of $20 \mathrm{rpm}$ for $5 \mathrm{~min}$ or until they fell off. The retention times were recorded after 4 weeks. On the testing day, each rat was subjected to two trials with an interval of $10 \mathrm{~min}$.

\section{Biomarker analysis}

At the end of the experimental period, the rats were starved for 12 h. Blood was sampled from the abdominal artery, and serum was centrifuged at 4,000 rpm for $15 \mathrm{~min}$. Serum testosterone levels were measured at 0 and 4 weeks using an ELISA kit (ENZO Life Sciences) in accordance with the manufacturer's instructions. Serum SHBG levels were measured using an ELISA kit (CloudClone Corp., Wuhan, Hubei, China) in accordance with the manufacturer's instructions. Serum DHEA-sulfate levels were measured using an ELISA kit (FineTest, Wuhan, Hubei, China) in accordance with the manufacturer's instructions. Serum PSA 
levels were measured using an ELISA kit (Cusabio, Houston, TX, USA) in accordance with the manufacturer's instructions.

\section{Statistical analysis}

Data are presented as the mean standard error of the mean (SEM) values. Data were statistically evaluated through one-way analysis of variance using the GraphPad Prism (GraphPad, Inc., San Diego, CA, USA) software. Differences between groups were assessed using Dunnett's multiple range tests. Statistical significance was considered at $p<0.05$.

\section{Results and Discussion}

\section{Testosterone levels in TM3 cells}

Leydig cells are testosterone-producing cells in the interstitial compartment of mammalian testes, which support spermatogenesis in seminiferous tubes [27]. Using TM3 cells, we evaluated testosterone production after treatment with $\mathrm{EMF}, \mathrm{CW}$, and mixtures of the two extracts in different ratios (Fig. 1). Each compound tested was used at concentrations of 50 or $100 \mu \mathrm{g} / \mathrm{mL}$. Treatment with EMF, CW, or mixtures of EMF and CW (ratio of 3:7, 5:5, and 7:3) at $100 \mu \mathrm{g} / \mathrm{mL}$ significantly increased the testosterone levels produced by TM3 cells $(p<0.001)$. Testosterone levels peaked upon treatment with a mixture of an EMF and CW extracts at various ratios compared to those on treatment with $\mathrm{CW}$ alone when the EMF:CW ratio was 3:7. Therefore, in this study, this 3:7 mixture was designated as EMCW and used for in vivo experiments.

\section{Body weights after EMCW treatment}

We investigated the effects of EMCW on TDS in rats for 4 weeks (50, 100 and $200 \mathrm{mg} / \mathrm{kg} /$ day, p.o.). Weekly changes in the body

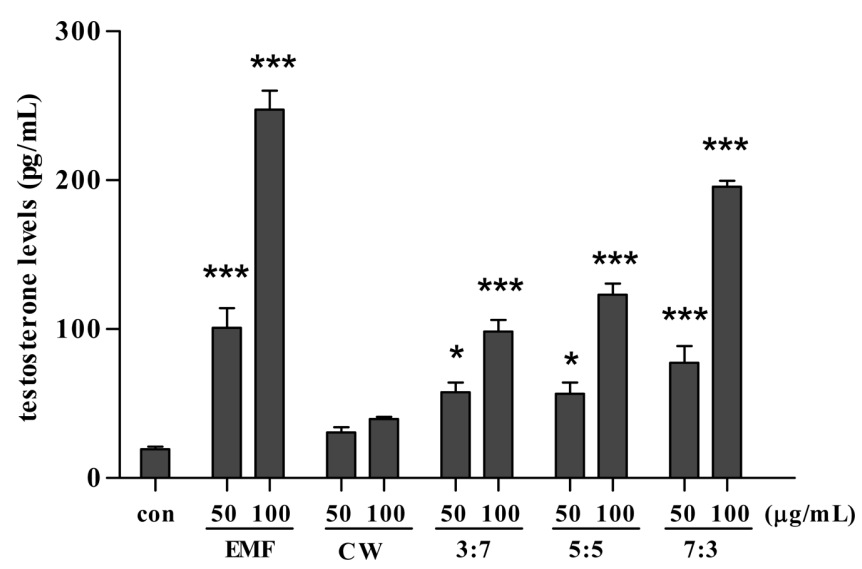

Fig. 1 Effects of EMF, CW, and mixtures of EMF and $\mathrm{CW}$ on testosterone production in TM3 cells. TM3 cells were treated for $24 \mathrm{~h}$ with various extracts (EMF, CW, 3:7, 5:5, or 7:3 mixtures). Data are presented as mean SE values. ${ }^{*} p<0.05,{ }^{*} * p<0.01$, and $* * * p<0.001$ compared to the control group

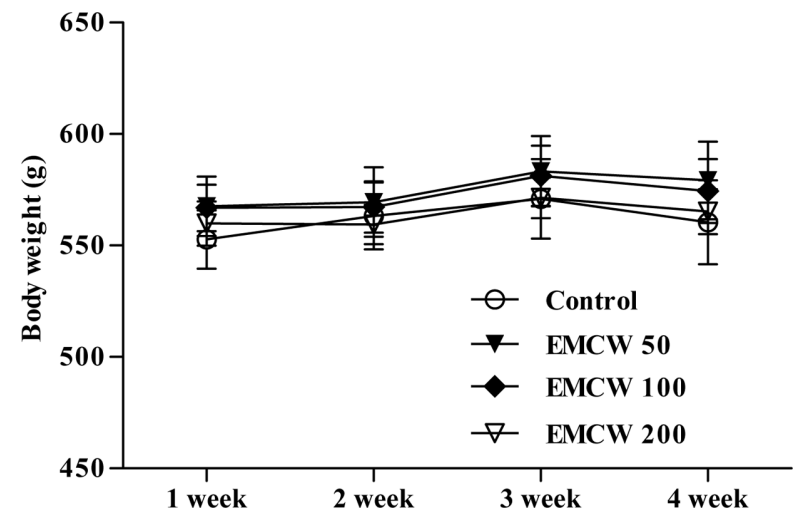

Fig. 2 Effects of EMCW on body weights of aging male rats. Data are represented as mean \pm SE values $(n=5)$. Control, no administration of $\mathrm{EMCW}$ (mixture of EMF and $\mathrm{CW}$ at the ratio of 3:7); EMCW 50, 50 $\mathrm{mg} / \mathrm{kg} /$ day EMCW; EMCW 100, $100 \mathrm{mg} / \mathrm{kg} /$ day EMCW; and EMCW 200, $200 \mathrm{mg} / \mathrm{kg} /$ day EMCW administered daily

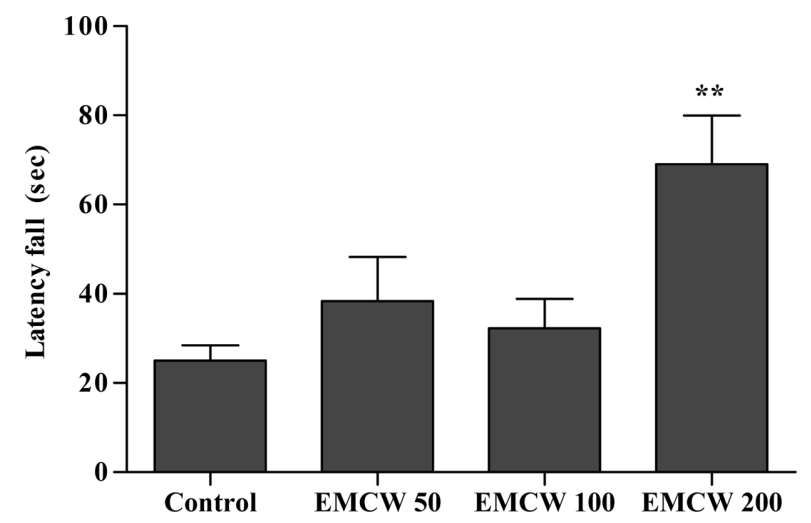

Fig. 3 Effects of EMCW on physical activity of aging male rats in a rotarod test. Control, no administration of EMCW (mixture of EMF and $\mathrm{CW}$ at the ratio of 3:7); EMCW 50, $50 \mathrm{mg} / \mathrm{kg} /$ day EMCW; EMCW 100, $100 \mathrm{mg} / \mathrm{kg} /$ day EMCW; and EMCW 200, $200 \mathrm{mg} / \mathrm{kg} /$ day EMCW administered daily. The data represent mean $\pm \mathrm{SE}$ values $(n=5)$. $* * p<0.01$ compared to the control group

weight of aging rats treated with EMCW are shown in Fig. 2. In all groups, the body weights gradually increased from week 1 until week 3. Furthermore, in all groups, the mean body weight decreased at 4 weeks. However, final body weights of the EMCW $(50,100$, and $200 \mathrm{mg} / \mathrm{kg} /$ day $)$-treated groups were not significantly different from those of the control groups.

\section{Effects of EMCW on the performance of aging rats in the rotarod test}

Testosterone enhances the physical locomotor capacity [28]. To evaluate the effects of EMCW on the adaptation of rat skeletal muscles to aging, tests were performed to assess physical strength. We investigated the effects of EMCW on the aging male rats using rotarod tests (Fig. 3). The latency to fall on the rotarod increased in the EMCW group compared with the control group. Moreover, the EMCW 200 group had significantly increased 

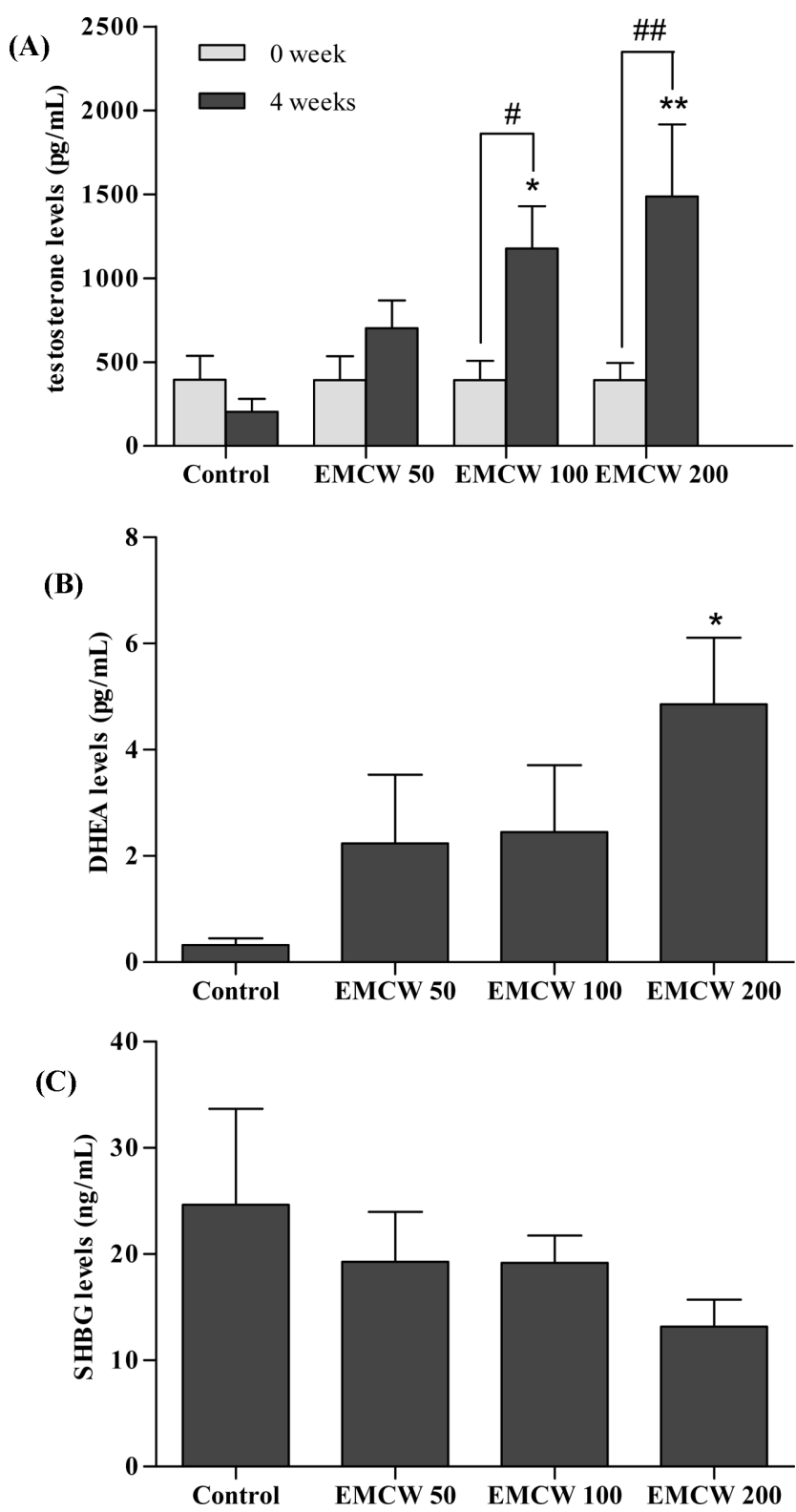

Fig. 4 Effects of EMCW on androgen levels in aging male rats: (A) testosterone, (B) DHEAs, (C) SHBG. Control, no administration of $\mathrm{EMCW}$ (mixture of $\mathrm{EMF}$ and $\mathrm{CW}$ at the ratio of 3:7); EMCW 50, 50 $\mathrm{mg} / \mathrm{kg} /$ day EMCW; EMCW 100, $100 \mathrm{mg} / \mathrm{kg} /$ day EMCW; and EMCW 200, $200 \mathrm{mg} / \mathrm{kg} /$ day EMCW administered daily. The data represent mean \pm SE values $(\mathrm{n}=5) .{ }^{*} p<0.05$ and $* * p<0.01$ compared to the control group. ${ }^{\#} p<0.05$, and ${ }^{\#} p<0.01$ compared to the EMCW group

retention time compared with the control group $(p<0.01)$.

\section{Effects of EMCW on androgen levels in aging rats}

TDS in aging men primarily results from reduced testosterone levels [29]. Therefore, we investigated the effects of EMCW on serum testosterone levels in aging male rats. As shown in Fig. 4A, the testosterone levels before the administration (week 0) were $394.22 \pm 142.84,393.15 \pm 140.78,393.03 \pm 114.95$, and $393.72 \pm 101.38$

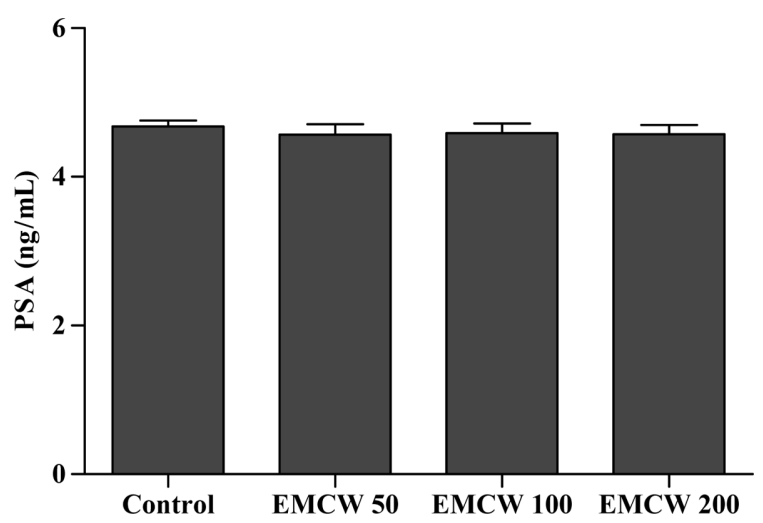

Fig. 5 Effects of EMCW on PSA levels in aging male rats. Control, no administration of EMCW (mixture of EMF and $\mathrm{CW}$ at the ratio of 3:7); EMCW 50, $50 \mathrm{mg} / \mathrm{kg} /$ day EMCW; EMCW 100, $100 \mathrm{mg} / \mathrm{kg} /$ day EMCW; and EMCW 200, $200 \mathrm{mg} / \mathrm{kg} /$ day EMCW administered daily. The data represent mean \pm SE values $(n=5)$

$\mathrm{pg} / \mathrm{mL}$ in the control, EMCW 50, EMCW 100, and EMCW 200 groups, respectively. Oral administration of 50,100 , and $200 \mathrm{mg} /$ $\mathrm{kg}$ /day EMCW significantly increased serum testosterone levels to $702.05 \pm 165.87,1175.72 \pm 251.81$, and $1487.40 \pm 427.75 \mathrm{pg} / \mathrm{mL}$, respectively, compared to the levels in the control group, which decreased to $203.93 \pm 75.77 \mathrm{pg} / \mathrm{mL}$ at 4 weeks compared to the levels at week 0. In the EMCW 100 and 200 groups, testosterone levels were significantly increased at 4 weeks compared to levels at week $(p<0.05$ and $p<0.01)$.

SHBG is a glycoprotein that maintains hormonal balance in the body and can bind to, transport, and inhibit testosterone function. When testosterone is bound to SHBG, it cannot be used by the body [30]. To investigate the effects of EMCW on serum SHBG levels in aging male rats, $\mathrm{EMCW}(50,100$, and $200 \mathrm{mg} / \mathrm{kg} /$ day) was administered daily for 4 weeks. Thereafter, SHBG were lower in EMCW than those in the control group (Fig. 4B). These results suggest that EMCW may play a significant positive role in the regulation of SHBG levels.

DHEA serves as a prohormone and can be rapidly metabolized within target tissues into biologically active steroids, including androstenedione, testosterone, and estradiol [31]. Accordingly, DHEA concentrations in the EMCW 200 group were significantly higher after 4 weeks of treatment than in the control group ( $p<0.05$, Fig. $4 \mathrm{C}$ ). Furthermore, testosterone levels were significantly higher in the EMCW 100 and 200 groups than that in the control group $(p<0.05$ and $p<0.01)$. These data reveal a significant increase in androgenic hormones such as testosterone and DHEA after treatment with EMCW $(p<0.05)$. These results suggest that EMCW potentially influences the production of DHEA, a precursor of steroid hormones, to consequently increase testosterone levels.

\section{Effects of EMCW on PSA in aging rats}

PSA is widely considered a tumor marker for screening and follow-up evaluation in prostate cancer [32]. Moreover, it serves 
as a safety marker for testosterone therapy. As shown in Fig. 5, serum PSA levels did not significantly differ from those in the control group. These results indicate that EMCW administration does not negatively influence the prostate.

Acknowledgments This research was supported by the Bio \& Medical Technology Development Program of the National Research Foundation (NRF) \& funded by the Korean government (MSIT) (No. 2019M3A9130 84518).

\section{References}

1. Hanker FD (1977) Sexual, psychic and physical complaints in 50 middle-aged men. Psychosomatics 18(5): 23-27

2. Harman SM, Metter EJ, Tobin JD (2001) Longitudinal effects of aging on serum total and free testosterone levels in healthy men. Baltimore Longitudinal Study of Aging. J Clin Endocrinol Metab 86(2): 724-731

3. Morales A, Schulman CC, Tostain JCW, Wu F (2006) Testosterone Deficiency Syndrome (TDS) needs to be named appropriately-the importance of accurate terminology. Eur Urol 50: 407-409

4. Wang C, Nieschlag E, Swerdloff R, Behre HM, Hellstrom L, Gooren LJ, Kaufman JM, Legross JJ, Lunenfeld B, Morles A, Morley JE, Schulman C, Thompson IM, Weidner W, Wu FCW (2009) ISA, ISSAM, EAU, EAA and ASA recommendations: Investigation, treatment and monitoring of late-onset hypogonadism in males. Int J Impot Res 21: 1-8

5. Haring R, Baumeister SE, Nauck M, Volzke H, Keevil BG, Brabant G, Wallaschocski H (2013) Testosterone and cardiometabolic risk in the general population the impact of measurement method on risk associations: a comparative study between immunoassay and mass spectrometry. Eur J Endocrinol 169(4): 1-22

6. Feldman HA, Longcope C, Derby CA (2002) Age trends in the level of serum testosterone and other hormones in middle-aged men: longitudinal results from the Massachusetts male aging study. J Clin Endocrinal Metab 87(2): 589-598

7. Su C, Rybalchenko N, Schreihofer DA, Singh M, Abbassi B, Cunningham RL (2011) Cell models for the study of sex steroid hormone neurobiology. J Steroid Hormone Sci 2: 1-9

8. Nieschlag E, Swerdloff R, Behre HM, Gooren LJ, Kaufman JM, Legros J-J (2005) Investigation, treatment and monitoring of late-onset hypogonadism in males. Int J Androl 8: 56-58

9. Sakamura F, Suga T (1987) Changes in chemical components of ripening oleaster fruits. Phytochemistry 26(9): 2481-2484

10. Kim JG (2006) Illustrated natural drugs encyclopedia. Namsandong, Seoul, Korea, p 279

11. Yoon KY, Hong JY, Nam HS, Moon YS, Shin SR (2007) Antioxidant activities and xanthine oxidase inhibitory effects of hot-water extracts from fruits of Elaeagnus multiflora Thunb. in maturity. J Korean Soc Food Sci Nutr 36(1): 14-19

12. Hong JY, Nam HS, Lee YS, Yoon KY, Kim NW, Shin SR (2006) Study on the antioxidant activity of extracts from the fruit of Elaeagnus multiflora Thunb. Korea J Food Preserv 13(3): 413-419

13. Kim SA, Oh SI, Lee MS (2007) Antioxidative and cytotoxic effects of solvent fractions from Elaeagnus multiflora. Korean J Food Nutr 20(2): 134-142

14. Kim NW, Joo EY, Kim SL (2003) Analysis on the components of the fruit of Elaeagnus multiflora Thunb. Korean J Food Preserv 10: 534-539
15. Hong JY, Nam HS, Lee YS, Kim NW, Shin SR (2006) Anti-oxidant activity of ethanol extracts from fruits of Elaeagnus multiflora Thunb. during maturation. Korean J Food Preserv 13(5): 643-648

16. Shin SR, Hong JY, Yoon KY (2008) Antioxidant properties and total phenolic contents of cherry elaeagnus (Elaeagnus multiflora Thunb.) leaf extract. Food Sci Biotechnol 17(3): 608-612

17. Lachowicz S, Kapusta I, Swieca M, Stinco CM, Melendez-Martinez AJ, Bieniek A (2020) In vitro biological activities of fruits and leaves of Elaeagnus multiflora Thunb. and their isoprenoids and polyphenolics profile. Antioxidants 9(5): 1-17

18. Jung MA, Jo AR, Shin JW, Kang HW, Kim YJ, Oh DR, Choi CY (2020) Anti-fatigue effects of Elaeagnus multiflora fruit extracts in mice. J Appl Biol Chem 63(1): 69-74

19. Choi DH, Lee YJ, Kim J S, Kang DG, Lee HS (2012) Cynanchum wilfordii ameliorates hypertension and endothelial dysfunction in rats fed with high fat/cholesterol diets. Immunopharmacol Immunotoxicol 34(1): 4-11

20. Lee HS, Choi JH, Kim YE, Kim IH, Kim BM, Lee CH (2013) Effects of the Cynanchum wilfordii ethanol extract on the serum lipid profile in hypercholesterolemic rats. Prev Nutr Food Sci 18(3): 157-162

21. Lee HS, Kim MH, Choi YY, Hong JK, Yang WM (2018) Effects of Cynanchum wilfordii on osteoporosis with inhibition of bone resorption and induction of bone formation. Mol Med Rep 17(3): 3758-3762

22. Shan L, Liu RH, Shen YH, Zang WD, Zhang C, Wu DZ, Min L, Su J, $\mathrm{Xu}$ XK (2006) Gastroprotective effect of a traditional Chinese herbal drug 'Bioshouwu on experimental gastric lesions in rat. J Ethnopharmacol 107(3): 389-394

23. Kim MS, Baek JH, Park JA, Hwang BY, Kim SE, Lee JJ, Kim KW (2005) Wilfoside KIN isolated from Cynanchum wilfordii inhibits angiogenesis and tumor cell invasion. Int J Oncol 26(6): 1533-1539

24. Yang SB, Lee SM, Park JH, Lee TH, Baek NI, Park HJ, Lee HJ, Kim JY (2014) Cynandion A from Cynanchum wilfordii attenuates the production of inflammatory mediators in LPS-induced BV-2 microglial cells via NF- $\kappa$ B inactivation. Biol Pharm Bull 37(8): 1390-1396

25. Lee GO, Kim JY, Pan SO, Kim M, Jun WJ, Choi CY (2016) Ahprodisiac property of the aqueous extract of Cynanchum wilfordii. $\mathrm{J}$ Food Nutr 4: 713-719

26. Lee GO, Shin JW, Choi HJ, Jo AR, Pan SO, Bae DH, Lee YW, Choi CY (2017) Cynanchum wilfordii ameliorates testosterone-induced benign prostatic hyperplasia by regulation 5a-reductase and androgen receptor activities in a rat model. Nutrients 9(10): 1-15

27. Mather JB (1980) Establishment and characterization of two distinct mouse testicular epithelial cell lines. Bio Reprod 23(1): 243-252

28. Sattler F, Bhasin S, He J, Chou CP, Castaneda-Sceppa C, Yarasheski K, Binder E, Schroeder ET, Kawakubo M, Zhang A, Roubenoff R, Azen S (2011) Testosterone threshold levels and lean tissue mass targets needed to enhance skeletal muscle strength and function: the HORMA trial. J Gerontol A Biol Sci Med Sci 66(1): 122-129

29. Noh YH, Kim SH, Kim JY, Park JA, Kim OH, Han DS, Kim WY, Kim SS, Lee MY, Heo SH, Kim MS, Lee WB, Jeong YH, Myung SC (2012) Improvement of andropause symptoms by dandelion and rooibos extract complex CRS-10 in aging male. Nutr Res Pract 6(6): 505-512

30. Shea JL, Wong PY, Chen Y (2014) Free testosterone: Clinical utility and important analytical aspects of measurement. Adv Clin Chem 63: 59-84

31. Arlt W, Haas J, Callies F, Reincke M, Hubler D, Oettel M, Ernst M, Schulte HM, Allolio B (1999) Biotransformation of oral dehydroepiandrosterone in elderly men: significant increase in circulating estrogens. J Clin Endocrinol Metab 84(6): 2170-2176

32. Wang MC, Valenzuela LA, Murphy GP, Chu TM (1979) Purification of a human prostate specific antigen. Invest Urol 17(2): 159-163 